\title{
Verantwortungsbewusster Umgang mit Medikamenten und Hygienemaßnahmen
}

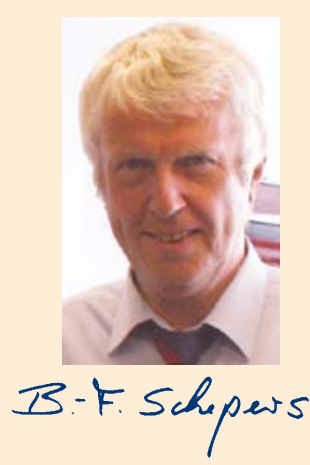

Liebe Kolleginnen und Kollegen,

mit der Entdeckung des Salvarsans, des Penicillins und der Sulfonamide schien in der ersten Hälfte des vergangenen Jahrhunderts ein neues Zeitalter in der Bekämpfung der Infektionskrankheiten eingeleitet zu sein und damit die Befreiung von der mittelalterlichen Geißel der Seuchen. Die Zunahme viral verursachter Massenerkrankungen ließ diese Annahme jedoch spätestens mit dem Auftreten des HI-Virus in den 1980er Jahren zweifelhaft erscheinen. Mehr noch wurde der Siegeszug der Medizin gegen die Infektionserkrankungen durch die bereits seit den 1960er Jahren zu beobachtende und inzwischen rasant zunehmende Resistenzbildung bakterieller Erreger in Frage gestellt. Inzwischen muss man schon von einem harten Kopf-an-Kopf-Rennen zwischen Resistenzbildungen und der Entwicklung neuer Antibiotika sprechen. Weltumspannender Handel und Tourismus haben dabei einen wesentlichen Anteil an der raschen weltweiten Verbreitung der Resistenzen, zumal ein sorgsamer, verantwortungsbewusster Umgang mit den Medikamenten oft nicht sichergestellt ist und angemessene Hygienemaßnahmen häufig nicht umgesetzt werden. Es ist daher nur zu begrüßen, dass mit dieser Ausgabe der FTR die zunehmende Problematik der Medikamentenresistenzen, eine der größten Herausforderungen unserer Zeit an die Medizin, aufgegriffen wird. Ich meine, dass alle Autoren dieses Schwerpunkthefts ihre Themen auf hohem Niveau und praxisnah umgesetzt haben und uns die problematischen Entwicklungen bewusst machen, die uns schon bald ereilen könnten. Mögen die Schwerpunktartikel auch primär der Tropen- und Reisemedizin zugeordnet werden, so berührt die Problematik aber durchaus auch die Bereiche Verkehrs-, Luftfahrt- und Schifffahrtmedizin und dürfte damit auf ein breites Interesse der FTR-Leserschaft stoßen.

So informiert der Beitrag von Dr. Philipp Zanger, Tübingen, über ungewöhnliche Resistenzmuster in der antibiotischen Therapie von eitrigen Hautinfektionen, die häufig bei Reiserückkehrern aus den Tropen auftreten.

Auch Gonorrhö, Syphilis und weitere sexuell übertragbare Erkrankungen sind weit verbreitet: Insbesondere bei Gonokokken besteht, so die Berliner Autoren Dr. Susanne Buder und Prof. Peter Kohl, derzeit die Gefahr, dass sich multiresistente Stämme entwickeln.

Zur medikamentösen Prophylaxe und Behandlung der Malaria finden Sie in diesem Heft ausführliche Informationen: Die Autoren, Dr. Nicole Berens-Riha und Prof. Hans Dieter Nothdurft, München, beschreiben die weltweite Resistenzlage und die derzeitigen Empfehlungen zur Prophylaxe sowie Notfalltherapien für jedes Medikament. Plasmodium falciparum hat bisher noch gegen jedes breit eingesetzte Malariamittel Resistenzen entwickelt. Auch die bisher vielversprechenden Artemisinine könnten bald ihre Wirksamkeit verlieren.

Dr. Alexander Zoufaly, Hamburg, schließt mit „HIV-Resistenzen in Afrika“ die Schwerpunktthemen ab: Das HI-Virus entwickelt so rasch Resistenzen, dass das Ziel weltweiter Programme, die hohe Anzahl der AIDS-Toten zu minimieren, gefährdet ist.

Ebenfalls ist in dieser Ausgabe eine Kasuistik aus meinem Fachgebiet, der maritimen Medizin, enthalten, deren Lektüre ich Ihnen besonders empfehle: Nach einer Schiffskollision gibt es einen Schwerverletzten und einen Vermissten - ihre Leben konnten trotz aller Anstrengungen nicht gerettet werden.

Herzliche Grüße aus Hamburg

Bernd-Fred Schepers 